\section{Persistent left superior vena cava: an overlooked feature of CHARGE syndrome?}

\author{
Paula Goldenberg, ${ }^{1}$ Amy Shikany, ${ }^{2}$ Ashley \\ Parrott, ${ }^{2}$ Stephanie M. Ware, ${ }^{3}$ Robert B. \\ Hinton $^{2}$ \\ 1 Medical Genetics, Division of Pediatrics, \\ Massachusetts General Hospital, Boston, \\ MA; ${ }^{2}$ Heart Institute, Division of \\ Cardiology, Cincinnati Children's Hospital \\ Medical Center, Cincinnati, $\mathrm{OH}$; \\ ${ }^{3}$ Departments of Pediatrics and Medical \\ and Molecular Genetics, Indiana \\ University School of Medicine, \\ Indianapolis, IN, USA
}

\begin{abstract}
CHARGE is a well-characterized syndrome (OMIM 2148400) associated with multiple congenital anomalies including cardiovascular malformations. Mutations in $C H D 7$ are the most common cause of CHARGE syndrome. Persistent left superior vena cava (LSVC) has been described in patients with CHARGE syndrome in one study of LSVC associations. A retrospective chart review was conducted for all patients with CHARGE syndrome, diagnosed by Blake criterion features and/or the presence of a pathogenic CHD7 mutation. Echocardiograms were performed on a clinical basis for all patients and were systematically reviewed and classified. Persistent LSVC was present in $50 \%$ of patients with CHARGE syndrome (4/8) and was seen in 3 out of 33 patients seen by cardiovascular genetics with $22 q 11.2$ deletion syndrome. Persistent LSVC is a common finding in patients with CHARGE syndrome and its presence may increase the index of suspicion in patients with other characteristic congenital anomalies.
\end{abstract}

\section{Introduction}

CHARGE syndrome (OMIM 2148400) is an autosomal dominant, multiple congenital anomaly syndrome. Typically, the occurrence is sporadic with rare familial cases. The term CHARGE itself is an acronym of common features in this syndrome, including ocular Coloboma, Heart defects, choanal Atresia, Retardation of growth and development, Genitourinary and Ear anomalies including deafness. The prevalence of CHARGE syndrome is estimated to be one in $8500-10,000$ live births. ${ }^{1}$ Cardiovascular malformations (CVMs) that are typically associated with this syndrome include conotruncal malformations [tetralogy of Fallot, double outlet right ventricle, D-transposition of the great arteries (TGA)], septal defects (atrial septal defects, ventriculoseptal defects), right ventricular outflow tract obstruction (RVOTO, e.g., pulmonary valve stenosis), and patent ductus arteriosus. ${ }^{2}$

CHARGE syndrome was formerly a clinical diagnosis based on particular major and minor findings. The schema most generally used was proposed by Blake et al., ${ }^{3}$ and there is an additional clinical criterion schema proposed by Verloes et al. (Table 1). ${ }^{4}$ Both systems utilize similar criteria: endocrine abnormalities (delayed pubertal development, gonadotropin or growth hormone deficiency), developmental delay or intellectual disability, and cranial nerve dysfunction, in addition to CVM.

Since 2004, the clinical diagnosis of CHARGE syndrome has been supported by sequencing of $\mathrm{CHD} 7,{ }^{5} \mathrm{Chromodomain} H$ Helicase DNA-binding protein active in the developing embryo. Among patients with a clinical diagnosis of CHARGE syndrome by Blake and/or Verloes criteria, over $90 \%$ have pathogenic mutations, deletions, or duplications of $C H D 7 .^{6}$ Patients with truncating mutations of $\mathrm{CHD} 7$ are more likely to both meet clinical criteria (Blake and/or Verloes), have CVMs, choanal atresia, and cleft lip/palate than patients with missense mutations of $\mathrm{CHD} 7$ ? $^{\text {? }}$

There is difficulty in making a clinical diagnosis of CHARGE syndrome in the cardiac intensive care unit (CICU) because newborns may not have observable threshold criterion features. Unifying diagnoses impact management and therefore timely diagnoses impact care. Additional congenital anomalies or specific CVMs that increase suspicion for CHARGE syndrome would be helpful in the assessment of newborns in the CICU.

The presence of left superior vena cava (LSVC) is common in the general population $(0.1-1.7 \%)^{8}$ and may be an asymptomatic congenital anomaly discovered in the course of evaluation for other conditions. LSVC is more commonly seen in individuals with concurrent CVMs (10\%). ${ }^{8,9}$ In particular, SVC abnormalities are common in individuals with heterotaxy syndromes,,$^{10}$ who may have a LSVC with or without a persistent right superior vena cava (bilateral SVC with or without a communicating vein). There is a high prevalence of extracardiac findings in patients with LSVC (51\%), and of these, $21 \%$ may have heterotaxy syndrome. ${ }^{8}$

Previously, Postema and colleagues reported a case series of 102 consecutive patients with LSVC in which five patients (5\%) with CHARGE syndrome were identified. ${ }^{11}$ In addition, unspecified SVC anomalies were reported in 5 patients (8\%) with CHARGE in an epidemiologic survey. ${ }^{1}$ Larger studies examining cardiac features in CHARGE syndrome have
Correspondence: Paula Goldenberg, Medical Genetics, Massachusetts General Hospital for Children, 175 Cambridge St., 5th Floor, Boston, MA 02114, USA

Tel.: 617.726.1742 - Fax: 617.724.1911.

E-mail: pgoldenberg2@partners.org

Key words: CHARGE syndrome; CHD7; persistent left superior vena cava; bilateral superior vena cava; congenital heart defects.

Contributions: PG, conception and design of work, drafted the manuscript with critical revisions, statistical analysis, final approval, accountable for all aspects of the work; AS, AP, acquisition of data, critical revisions, final approval of manuscript, accountable for all aspects of work; SW, analysis and interpretation of data, critical revisions, final approval of manuscript, accountable for all aspects of work; RH, acquisition of cardiologic data with analysis and interpretation, critical revisions, final approval of manuscript, accountable for all aspects of work.

Conflict of interest: there are no conflicts of interest to disclose.

Received for publication: 9 September 2015 Revision received: 12 November 2015. Accepted for publication: 22 November 2015.

This work is licensed under a Creative Commons Attribution NonCommercial 3.0 License (CC BYNC 3.0).

(C) Copyright P. Goldenberg et al., 2015

Licensee PAGEPress, Italy

Cardiogenetics 2015; 5:5511

doi:10.4081/cardiogenetics.2015.5511

not routinely documented SVC findings, ${ }^{2,12-14}$ thus the true frequency of LSVC in patients with CHARGE syndrome is unknown.

We reviewed patients with CHARGE syndrome seen by the cardiovascular genetics service at CCHMC to determine the frequency of venous anomalies. We hypothesized that there is an increased frequency of LSVC in patients with a diagnosis of CHARGE syndrome.

\section{Materials and Methods}

A retrospective case series of consecutive patients with a clinical and/or molecular diagnosis of CHARGE syndrome and 22q11.2 deletion syndrome followed by the cardiovascular genetics service at CCHMC from 7/2010$12 / 2012$ was completed with Institutional Review Board approval. Blake criteria were ascertained and typical CHARGE was used as the standard for clinical diagnosis. We also evaluated for Verloes criteria in all patients as 
these are weighted differently (Table 1). Pathogenic mutations of $C H D 7$ were the standard for laboratory-confirmed diagnosis. All initial echocardiograms were reviewed by a cardiologist, and CVMs were classified using an established taxonomy that identifies both specific lesions and groups of related lesions. ${ }^{15}$ As a comparison cohort, patients with $22 \mathrm{q} 11.2$ deletion syndrome, a condition with similar phenotype, ${ }^{16}$ were evaluated similarly.

\section{Results}

Eight patients were ascertained with CHARGE syndrome (4 female, 7 Caucasian non-Hispanic, 1 African American). There was an equal distribution of gender and median age at diagnosis of approximately 3 months ( 0.26 years), however two subjects were ascertained much later at 1.73 years and 12.30 years in a cardiac neurodevelopmental clinic (Table $2)$. The $22 q 11.2$ deletion syndrome comparison group had 33 patients with demographics similar to the CHARGE cohort (18 female, 30 Caucasian with one Hispanic, 2 African American, 1 Asian). All patients with $22 q 11$ Deletion syndrome had typical deletions by fluorescent in situ hybridization (FISH) or microarray studies, were consecutively ascertained during the same time period, and were also followed by the cardiovascular genetics service.

In the CHARGE cohort, the CVM group was predominantly conotruncal and included septal defects and RVOTOs (Table 3). Four patients with CHARGE (4/8; 50\%) had persistent LSVC (bilateral SVC), three patients with LSVC had TGA with additional cardiac defects. Interestingly, 5/8 patients (1-5, Table 2), including all four with LSVC, had cardiac findings consistent with a laterality disorder, a classification that encompasses heterotaxy syndromes. In contrast, three of the $22 q 11.2$ deletion syndrome cohort had LSVC (9\%). The 22 q11 deletion syndrome cohort had the following CVM groups: 22 conotruncal, 6 septal, 1 RVOTO, 4 other [abberrant subclavian artery (3), and vascular ring (1)].

Patient 1 did not meet Blake criteria, but did meet Verloes criteria as atypical CHARGE (Table 2). We did include this patient based on the pathogenic molecular findings of a splice site mutation that would truncate CHD7; interestingly, this patient did not have persistent LSVC.

The one patient without a pathogenic CHD7 mutation, Patient 4, also had normal microarray and 22q11 FISH testing. LSVC was present and this patient had typical features of CHARGE including choanal stenosis, growth delay (length $0.2 \%$ at 6 months of life), striking ear anomalies (right microtia, left anotia, absent left tympanic membrane, malrotated left middle ear ossicles fused to the inferior wall, dysmorphic stapes, hypoplastic oval window, right incus fused to lateral wall, superior semicircular canal partially absent, dysmorphic, and large undeveloped horizontal semicircular canal), severe to profound hearing loss bilaterally (conductive hearing loss ipsilateral to anotia), cranial nerve anomalies (absent right facial nerve and tortuous left facial nerve) with broad forehead and square facies. Cardiac findings are listed in Table 3. No colobomas were seen on ophthalmologic evaluation. This patient also had additional rare and severe craniofacial findings including absent left internal carotid artery and absent left parotid gland, some of which have been previously described in the case report literature in association with CHARGE syndrome. ${ }^{17}$ This patient met Blake and Verloes criteria for a clinical diagnosis of typical CHARGE syndrome, and may be one of the $<10 \%$ of patients meeting this standard that do not have mutations of $C H D 77^{7}$

All patients had unique phenotypic features. Molecular findings of all patients showed a preponderance of splice site and premature stop codon mutations.

\section{Discussion and Conclusions}

Early diagnosis of genetic syndromes is important for optimal patient care in the CICU setting, as knowledge of a unifying diagnosis informs medical decision making, perioperative care, identification and management of comorbidities, improved attention to feeding difficulty in patients with increased risk of dysphagia, and postoperative rehabilitative therapy.

Establishing a diagnosis of CHARGE syndrome in a newborn may be delayed by failure to meet full clinical diagnostic schema in infancy, delay in molecular testing, and/or features that overlap with more common or wellknown genetic syndromes such as 22q11.2 deletion syndrome. Usually in newborn care, unless suggested by genetics consult, teams will not routinely order an ophthalmology consult that may detect a retinal coloboma, facial bone imaging for unilateral choanal atresia, or audiology testing that might lead to the diagnosis of CHARGE syndrome in a newborn with conotruncal defects. Identification of additional features, which increase suspicion for CHARGE syndrome and assist in delineating it from other common syndromes, would assist in identifying patients who should have CHD7 sequencing, and in appropriate diagnosis of patients who may be too young to meet the clinical criteria of CHARGE syndrome.

This study identifies LSVC as a possible new phenotypic association for CHARGE syndrome. Echocardiograms are routinely performed to

Table 1. Comparison of clinical criteria for CHARGE syndrome.

\begin{tabular}{|c|c|c|c|}
\hline Author & Major criteria & Minor criteria & Clinical diagnosis \\
\hline Blake $^{3}$ & $\begin{array}{l}\text { 1. Coloboma, microphthalmia } \\
\text { 2. Choanal atresia or stenosis } \\
\text { 3. Characteristic external ear anomaly, } \\
\text { middle/inner ear malformations, mixed deafness } \\
\text { 4. Cranial nerve dysfunction }\end{array}$ & $\begin{array}{l}\text { 1. Cardiovascular malformations } \\
\text { 2. Tracheo-esophageal defects } \\
\text { 3. Genital hypoplasia or delayed pubertal development } \\
\text { 4. Cleft lip and/or palate } \\
\text { 5. Developmental delay } \\
\text { 6. Growth retardation } \\
\text { 7. Characteristic face }\end{array}$ & $\begin{array}{l}\text { Typical CHARGE: } \\
4 \text { major or } \\
3 \text { major }+3 \text { minor }\end{array}$ \\
\hline Verloes $^{4}$ & $\begin{array}{l}\text { 1. Ocular coloboma } \\
\text { 2. Choanal atresia } \\
\text { 3. Hypoplastic semicircular canals }\end{array}$ & $\begin{array}{l}\text { 1. Heart or esophageal malformation } \\
\text { 2. Malformation of the middle or external ear } \\
\text { 3. Rhombencephalic dysfunction including } \\
\text { sensorineural deafness } \\
\text { 4. Hypothalamo-hypophyseal dysfunction } \\
\text { (gonadotropin or growth hormone deficiency) } \\
\text { 5. Mental retardation }\end{array}$ & $\begin{array}{l}\text { Typical CHARGE } \\
3 \text { major or } \\
2 \text { major }+2 \text { minor } \\
\text { Partial CHARGE } \\
2 \text { major + } 1 \text { minor } \\
\text { Atypical CHARGE } \\
2 \text { major + } 0 \text { minor or } \\
1 \text { major + } 1 \text { minor }\end{array}$ \\
\hline
\end{tabular}


screen for cardiac defects in patients suspected of having CHARGE syndrome, so this information would be available and accessible to geneticists and cardiologists. In our small retrospective review we have found a high proportion of patients with CHARGE syndrome who had persistent LSVC, suggesting that this anomaly in the presence of another cardinal feature of CHARGE syndrome might trigger further clinical suspicion for this syndrome. Defining the frequency of LSVC in CHARGE is therefore important to this end. Other syndromes on the differential diagnosis for LSVC include heterotaxy, VACTERL association, aneuploidy, and 22q11.2 deletion syndrome. ${ }^{11}$

Consideration of a potential unifying mechanism of the occurrence of LSVC in CHARGE patients suggests there is some degree of phenotypic overlap between CHARGE syndrome and laterality defects. Specific types of CVMs, including complex CVM are present in both situations, but CVMs that are common and largely present in patients without a genetic syndrome (such as conotruncal defects) do not necessarily alter the index of suspicion like specific CVMs. Our patient population had a higher than expected prevalence of TGA and right aortic arch. Most, but not all, patients with either of these CVMs also had LSVC. Interestingly, mal-arrangement in addition to structural defects is present in both conditions, suggesting consideration of arrangement may also facilitate identification of CHARGE patients. Patient 4 had additional cardiac features consistent with heterotaxy, including dextrocardia and total anomalous pulmonary venous connection. Laterality defects have been seen in $C H D 7$ knockdown zebrafish, ${ }^{18}$ as well as more typical cardiac anomalies similar to those generally seen in patients with CHARGE syndrome. ${ }^{19}$ It may be that $C H D 7$ plays a role in left-right discrimination in human cardiac development.

Limitations of this study include the fact that all patients were ascertained based on their CVMs, and we are therefore unable to assess whether patients with CHARGE syndrome may have isolated LSVC. All of the patients in this study had CVMs, whereas 75\% of patients with CHARGE syndrome have CVMs ${ }^{2}$ reflecting the ascertainment of patients from a cardiovascular genetics service. Additionally, the small sample size of individuals with CHARGE syndrome in this study may overestimate this association and not be generalizable. Arguing against sampling bias, however, is the high prevalence of CHARGE syndrome in an LSVC population study ${ }^{11}$ and increased SVC anomalies in an epidemiologic study of patients with CHARGE syndrome. ${ }^{1} \mathrm{~A}$ point may be made that the frequency of this finding is related to the $10 \%$ prevalence of LSVC in patients with CVMs, however in reviewing our patient group with $22 q 11$ dele-

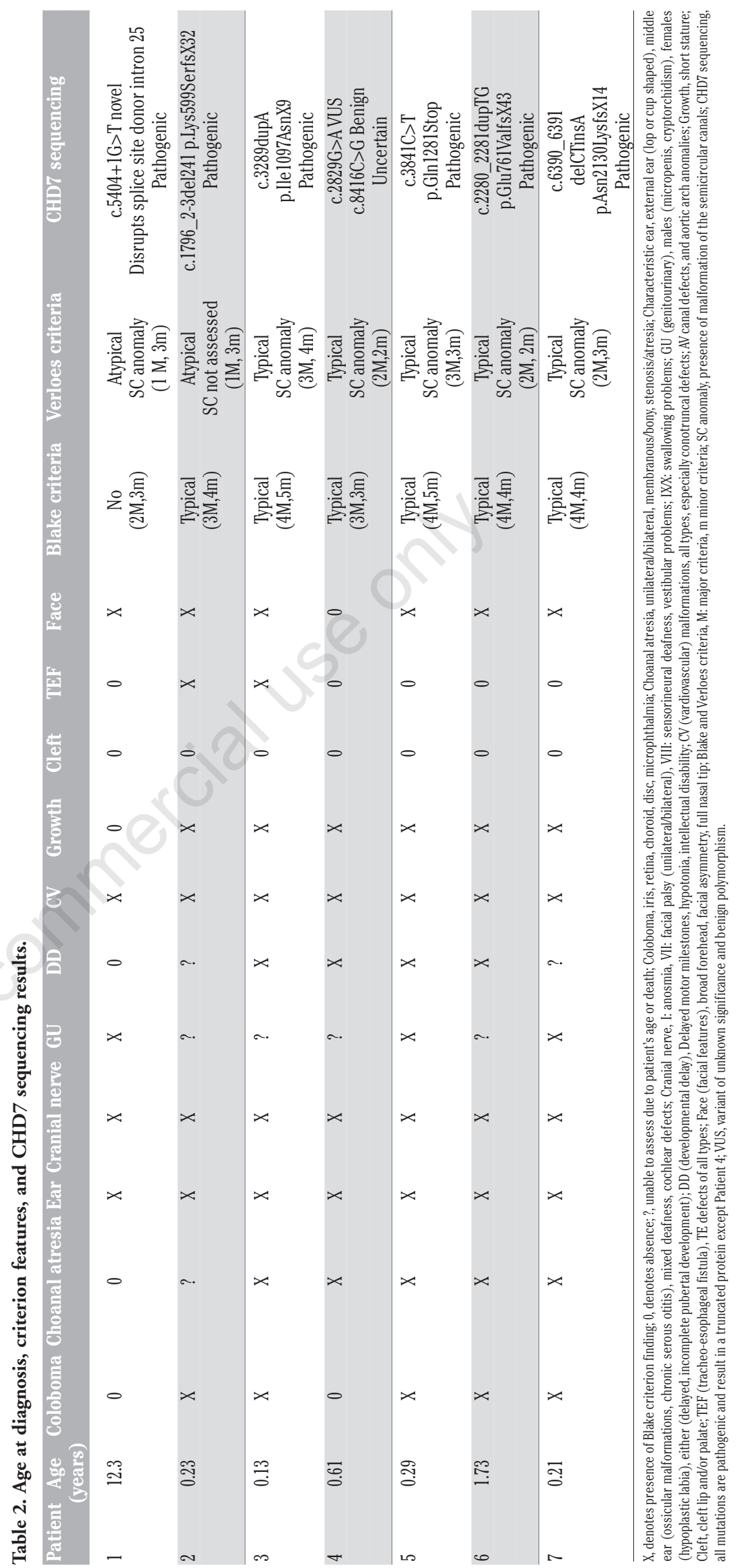

[Cardiogenetics 2015; 5:5511] 
Table 3. Cardiovascular malformation and left superior vena cava status.

\begin{tabular}{|c|c|c|c|}
\hline Patient & CVM groups & CVM lesions & LSVC \\
\hline 1 & $\begin{array}{l}\text { Conotruncal } \\
\text { RVOTO }\end{array}$ & $\begin{array}{l}\text { Double outlet right ventricle } \\
\text { Pulmonary valve stenosis } \\
\text { Right aortic arch }\end{array}$ & - \\
\hline 2 & $\begin{array}{l}\text { Conotruncal } \\
\text { Septal }\end{array}$ & $\begin{array}{l}\text { Interrupted aortic arch, type B } \\
\text { Ventricular septal defect } \\
\text { Aberrant right subclavian artery }\end{array}$ & - \\
\hline 3 & Septal & $\begin{array}{l}\text { Atrial septal defect } \\
\text { Patent ductus arteriosus }\end{array}$ & - \\
\hline 4 & $\begin{array}{l}\text { Conotruncal } \\
\text { APVR } \\
\text { RVOTO }\end{array}$ & $\begin{array}{l}\text { Dextrocardia } \\
\text { D-Transposition of the great arteries } \\
\text { Total anomalous pulmonary venous return } \\
\text { Tricuspid stenosis }\end{array}$ & + \\
\hline 5 & $\begin{array}{l}\text { Conotruncal } \\
\text { RVOTO }\end{array}$ & $\begin{array}{l}\text { D-Transposition of the great arteries } \\
\text { Pulmonary valve stenosis }\end{array}$ & + \\
\hline 6 & Septal & $\begin{array}{l}\text { Ventricular septal defect } \\
\text { Patent ductus arteriosus }\end{array}$ & - \\
\hline 7 & Conotruncal & $\begin{array}{l}\text { Double outlet right ventricle } \\
\text { Mitral atresia } \\
\text { Right aortic arch }\end{array}$ & + \\
\hline 8 & Conotruncal & $\begin{array}{l}\text { D-Transposition of the great arteries } \\
\text { Right aortic arch } \\
\text { Aberrant left subclavian artery }\end{array}$ & + \\
\hline
\end{tabular}

CVM, cardiovascular malformation; LSVC, left superior vena cava; RVOTO, right ventricular outflow tract obstruction; APVR, right aortic arch, dextrocardia.

tion with CVMs ( $\mathrm{n}=33)$ we found three patients with LSVC (11\%), similar to the general presence of LSVC in individuals with CVMs. Larger studies of SVC anomalies in CHARGE syndrome patients are required to clarify these limitations.

In summary, we have identified LSVC as a likely common cardiovascular malformation in CHARGE, suggesting CHD7 plays a role in venous development. Other findings suggestive of abnormal development of laterality were also found in our population (right aortic arch, dextrocardia, D-TGA). Taken together with the abnormal laterality development in zebrafish with CHD7 knockdown, an additional role for CHD7 in early embryonic left-right patterning may be considered. CHARGE syndrome should be considered when LSVC and laterality abnormalities are identified.

\section{References}

1. Issekutz KA, Graham JM, Jr., Prasad C, et al. An epidemiological analysis of CHARGE syndrome: preliminary results from a Canadian study. Am J Med Genet Part A 2005;133A:309-17.

2. Corsten-Janssen N, Kerstjens-Frederikse WS, du Marchie Sarvaas GJ, et al. The cardiac phenotype in patients with a CHD7 mutation. Circ Cardiovasc Genet 2013;6:248-54.

3. Blake KD, Davenport SL, Hall BD, et al. CHARGE association: an update and review for the primary pediatrician. Clin Pediatr 1998;37:159-73.

4. Verloes A. Updated diagnostic criteria for CHARGE syndrome: a proposal. Am J Med Genet Part A 2005;133A:306-8.

5. Vissers LE, van Ravenswaaij CM, Admiraal $\mathrm{R}$, et al. Mutations in a new member of the chromodomain gene family cause CHARGE syndrome. Nature Genet 2004;36: 955-7.

6. Jongmans MC, Admiraal RJ, van der Donk KP, et al. CHARGE syndrome: the phenotypic spectrum of mutations in the CHD7 gene. J Med Genet 2006;43:306-14.

7. Bergman JE, Janssen N, Hoefsloot LH, et al. CHD7 mutations and CHARGE syndrome: the clinical implications of an expanding phenotype. J Med Genet 2011;48:334-42.

8. Perles Z, Nir A, Gavri S, et al. Prevalence of Persistent Superior Vena Cava and Association With Congenital Heart Anomalies. Am J Cardiol 2013;112:1214-8.

9. Edwards JDJ. Thoracic venous anomalies. Arch Pathol 1950;49:514-37.

10. Lin AE, Krikov S, Riehle-Colarusso T, et al. Laterality defects in the national birth defects prevention study (1998-2007): birth prevalence and descriptive epidemiology. Am J Med Genet A 2014; 164A:2581-91.

11. Postema PG, Rammeloo LA, van Litsenburg R,et al. Left superior vena cava in pediatric cardiology associated with extra-cardiac anomalies. Int $\mathrm{J}$ Cardiol 2008;123:302-6.

12. Lin AE, Chin AJ, Devine W, et al. The pattern of cardiovascular malformation in the CHARGE association. Am J Dis Child 1987;141:1010-3.

13. Tellier AL, Cormier-Daire V, Abadie V, et al. CHARGE syndrome: report of 47 cases and review. Am J Med Genet 1998;76:402-9.

14. Wyse RK, al-Mahdawi S, Burn J, Blake K. Congenital heart disease in CHARGE association. Pediatr Cardiol 1993;14:75-81.

15. Botto LD, Lin AE, Riehle-Colarusso T, et al. Seeking causes: classifying and evaluating congenital heart defects in etiologic studies. Birth Defects Res A Clin Mol Teratol 2007;79:714-27.

16. Corsten-Janssen N, Saitta SC, Hoefsloot $\mathrm{LH}$, et al. More clinical overlap between 22q11.2 deletion syndrome and CHARGE syndrome than often anticipated. Mol Syndromol 2013;4:235-45.

17. Ormitti F, Ventura E, Bacciu A, et al. Unilateral ectopic parotid gland in CHARGE syndrome. Pediatr Radiol 2013;43:247-51.

18. Jacobs-McDaniels NL, Albertson RC. Chd7 plays a critical role in controlling left-right symmetry during zebrafish somitogenesis. Develop Dynamics 2011;240:2272-80.

19. Patten SA, Jacobs-McDaniels NL, Zaouter $\mathrm{C}$, et al. Role of Chd7 in zebrafish: a model for CHARGE syndrome. PLoS One 2012;7:e31650. 